Vol.: 4 Issue: 2 Date: 31.12.2020 Received: 2.12.2020 Accepted: 24.12.2020 Final Version: 28.12.2020

ISVOS Journal, 2020, 4(2): 90-96 - https://doi.org/10.47897/bilmes.827955

\title{
Investigating the Relationship between the Opinions of Mothers with Infants in Intensive Care Unit on Human Milk Banking and their Religious Attitudes
}

\author{
Özgür Alparslan ${ }^{\mathrm{a}, 1}$, Gülçin Bozkurt ${ }^{\mathrm{b}}$ \\ ${ }^{a}$ Faculty of Health Sciences, Tokat Gaziosmanpaşa University,Tokat, Turkey \\ ORCID ID: 0000-0002-2264-2886 \\ ${ }^{\mathrm{b}}$ Faculty of Health Sciences, Istanbul University, Istanbul,Turkey \\ ORCID ID: 0000-0002-8528-2232
}

\begin{abstract}
The aim of this study is to determine the relationship between the opinions of mothers with newborns in intensive care unit on human milk banking and their religious attitudes. Designed in a descriptive and cross-sectional type (June-November 2015). The study was conducted on 200 mothers who agreed to participate in the study. The data were collected using the Religious Attitude Scale and an information form. It was determined that the mothers' $4 \%$ gave another mother's milk to their babies, and that $95 \%$ did not give their own milk to other babies. It was found that $32 \%$ of the mothers stated they would not be willing to donate milk if a milk bank opened, while $69 \%$ of this proportion did not favor the donation due to religious milk kinship. No statistically significant relation was found between parents' education, employment status, family type, number of children and scale scores ( $>$ >.05). It was concluded that the religious orientations of the mothers influenced their attitudes towards human milk banks, and that did not have a positive perspective on human milk banking. When the test results were examined, it was found that the only variable that was a significant predictor on the religious attitude was "obtaining milk from the bank when needed".
\end{abstract}

Keywords: "Donor milk, human milk bank, intensive care unit, milk kinship, religious attitude"

\section{Introduction}

In recent years, there has been an increase in the number of risky newborns all over the world and in our country. It has been reported that 5-13\% of babies born in the US and European countries are premature Goldenberg et al. [5] and that with increased maternal age, this risk is increasing [1-4]. Some infants may not be breastfed due to some reasons such as separation of the mother and the baby because of the risks associated with the mother or the baby, inadequate social support, insufficiency of sucking reflex, nutritional intolerance and problems [6]. The Human Milk Bank (HMB) is an important source particularly for risky newborns, who cannot be breastfed for various reasons. It is recommended that a HMB should be established near (NICU), breast milk should be collected and stored here, and that hospitalized infants should be feed on their mother milk [7]. In many developed countries in the US and Europe, HMB has been used as part of the standard care in neonatal NICU for a long time [4].

In studies comparing the effects of donor milk and formula in premature infants, while it has been determined that feeding the infants on donor milk has reduced the risk of NEC development and shortened the length of hospitalization [4,8,9]. Although considerable effort is spent in Turkey to ensure the infants in the NICUs are fed with breast milk, there are no suitable HMBs in compliance with international standards. HMB was established in Turkey in 2013 and is expected to make legal arrangements for the expansion of the Ministry of HMB. Because most of the population in our country is Muslim (99\%), most of the population may oppose HMB due to their religious attitudes. According to Muslim belief, in the case of a baby who is breastfed by another woman, although this baby is not a relative of blood, it is accepted as the brother of the children of the donor and cannot be married [10].

There are quite different opinions about breastfeeding in terms of medical and socio-cultural perspectives in our country. Especially in rural settlements, wet nursing is traditionally practiced in cases where the mother cannot breastfeed for any reason. Both sides need to know each other well for a wet nurse to be approved. Accordingly, it is thought that a maternal bond has formed between the infant and the donor and that the infant and the children of the donor are siblings thereafter. According to

\footnotetext{
${ }^{1}$ Corresponding author. Tel.: +05438239044.
}

E-mail address: ozgralp60@gmail.com 
this traditional approach, children who have milk kinship cannot get married. This problem needs to be addressed with a culturespecific approach and a solution should be produced [12].

The traditional and cultural attitudes and beliefs of parents about baby nutrition with milk from milk banks should be investigated [11]. No research into the relationship between attitudes towards HMB and religious orientation was found for the Turkish setting. Therefore, this study aimed to investigate the relationship between the attitudes of mothers with infants in NICU on HMB and their religious orientations.

\subsection{Material and Methods}

The universe of this descriptive and cross-sectional study consisted of 1289 mothers who had infants in the NICU of a university hospital $(\mathrm{N}=691)$ and a state hospital $(\mathrm{N}=598)$ between June-November 2015. The sampling size was calculated to be about 196 subjects for a single sampling with $80 \%$ power, 5\% error margin, and $6.1 \%$ effect size. The sampling, on the other hand, was made up of 200 mothers who met the sampling selection criteria and agreed to participate in the study.

The sampling inclusion criteria was that mothers would not have any mental or physical problems that would prevent them from understanding the questions correctly.

\subsection{Data collection and data collection tools}

The study used the Religious Attitude Scale and an information form questioning the socio-demographic characteristics designed by the researchers. The mothers were administered the data collection tools through face-to-face interviews.

The Information Form: This form consisted of 18 open-or closed-ended items questioning the gender and age of mothers and infants; descriptive features of the mothers such as education, employment status, and number of children; opinions and attitudes about breast milk banking such as donating breast milk to others' babies or giving the baby others' breast milk, and reasons for accepting/rejecting breast milk from a HMB.

Religious Attitude Scale (RAS): The "RAS" developed by Onay [13] was used to determine the religious attitude of the participating. The scale has been developed to quantify the extent to which religion has taken place in the lives of adults. Religious attitude is regarded as the level of the impact of individuals' religious beliefs, knowledge, and acceptance on their own feelings, thoughts, and behaviors. The scale is a four-point (never, sometimes, often, always) likert-type measure consisting of three dimensions (thoughts, behaviors, and emotions). It has a total of 18 items, 12 of which are positive structured and 6 of which were reversed. Increasing scores indicate rising religious attitudes, whereas decreasing scores mean falling religious attitude (the Cronbach Alpha: 0.95).

\subsection{Ethical considerations}

Necessary permission (Ethics board no: 15-KAEK-117) was obtained from the related hospital management and the ethics committee. The use of human cases in the study require the protection of individual rights, so the relevant ethical principles were strictly taken into consideration.

\subsection{Data analysis}

The data obtained at the end of the study were analyzed in SPSS 21.0 software package. In addition to descriptive statistical methods, student t test and Mann Whitney U test was used. Factors related to religious orientation were analyzed using simple linear regression. Factors related to religious orientation were analyzed using simple linear regression. Statistical significance of each analysis was determined at $\mathrm{p}<0.05$

\subsection{Limitations}

Responses from participants may not be representative of the target population being studied and the results cannot be generalized to other mothers and infants.

\section{Results}

Mothers in the study group were in 16-45 age range and the mean age was $27.68 \pm 5.96$. The infants of $66.5 \%$ ( $\mathrm{n}=133$ ) of the mothers were in the university hospital, while the newborns of $33.5 \%(n=67)$ were in the state hospital. Table 1 presents the 
demographic and obstetric characteristics of the mothers in the study group. While $2.5 \%$ of the mothers were illiterate, $46 \%$ were primary school graduates, $30 \%$ were secondary school graduates, and $21.5 \%$ were university graduates. In addition, $62.0 \%$ of them had core family structure and $86.5 \%$ were housewives. $27.5 \%$ of the parents had at least one pregnancy while $28 \%$ had two pregnancies.

Table 1. Demographic and obstetric characteristics of the mothers in the study group (N:200)*

\begin{tabular}{ccc}
\hline Characteristics & $\boldsymbol{N}$ & \% \\
\hline Mother's education & 5 & 2.5 \\
Illiterate & 54 & 46.0 \\
Primary education & 98 & 30.0 \\
Secondary education & 43 & 21.5 \\
Higher education & 27 & 13.5 \\
\hline Employment status of the mother & 173 & 86.5 \\
Employed & & 62.0 \\
Unemployed & 124 & 38.0 \\
\hline Family structure & 76 & 27.5 \\
Core family & & 28.0 \\
Extended family & 55 & 19.0 \\
Number of pregnancies & 56 & 13.5 \\
One & 38 & 12.0 \\
Three & 27 & 24 \\
Four & & \\
\hline
\end{tabular}

"Mean mother age: $27.68 \pm 5.96$

It was found that $96 \%(n=192)$ of the mothers did not feed their baby with another mother's breast milk, 4\% ( $\mathrm{n}=8)$ gave their baby another mother's breast milk, and that $95 \%(n=190)$ did not give their own breast milk to other babies. It was also determined that $95 \%$ of the mothers had heard about HMB previously and that $73 \%(n=146)$ wanted HMB in our country. In addition, 52.6\% $(\mathrm{n}=106)$ of the mothers stated that they could get milk from a HMB when they failed to provide breast milk for their babies. $74.5 \%(n=79)$ recognized the benefit of breast milk. $25.5 \%(n=27)$ said they could get milk for the health and development of their babies. On the other hand, the mothers stated they wouldn't get breast milk from others they didn't know well and that they did not approve milk kinship from a religious perspective $(\% 47,4)(n=94)$, they didn't want to get breast milk from others $(53,2 \% ; \mathrm{n}=50)$, breast milk from others might not be hygienic $(25,5 \% ; \mathrm{n}=24)$, diseases could transfer from others' milk $(17,0 \% ; \mathrm{n}=16)$, and that they did not want to donate milk because their milk was sufficient $(4,3 \% ; \mathrm{n}=4)$.

It was determined that $32 \%(n=64)$ of the mothers would not make breast milk donations if a milk bank was opened in our country. When the reason why they didn't want to donate was questioned, the following responses were obtained: "I do not want a religion based milk kinship", 69\% ( $\mathrm{n}=44)$; "my breast milk is inadequate", 25\% $(\mathrm{n}=16)$; and "diseases can spread through breast milk, not hygienic, not healthy", $5 \%(n=3)$. When the responses and scale scores were compared, no significant relationship was found between them $(\mathrm{p}>0,05)$.

When the subscale scores of the RAS were compared to willing to get milk from the HMB, it was found that subscale scores and total scale scores of the RAS were found to be statistically significantly higher $(\mathrm{p}<0.05)($ Table 2$)$. 
Table 2. Comparison between RAS and the variables such as getting milk from HMB, agreeing to donate breast milk to HMB, and giving breast milk to others' babies

\begin{tabular}{|c|c|c|c|}
\hline $\begin{array}{c}\text { Subscales of the Religious } \\
\text { Attitudes Scale }\end{array}$ & $\begin{array}{c}\text { Getting milk from the Breast Milk } \\
\text { Bank }\end{array}$ & $\bar{x}_{ \pm S S}$ & $t^{*} ; p$ \\
\hline \multirow[t]{2}{*}{ Thoughts } & Yes & $29.55 \pm 2.19$ & -2.005 \\
\hline & No & $30.13 \pm 1.85$ & .044 \\
\hline \multirow[t]{2}{*}{ Behaviors } & Yes & $18.48 \pm 2.80$ & -2.673 \\
\hline & No & $18.51 \pm 2.63$ & .000 \\
\hline \multirow[t]{2}{*}{ Emotions } & Yes & $14.42 \pm 1.79$ & -3.259 \\
\hline & No & $15.14 \pm 1.19$ & .000 \\
\hline Total score for the Religious & Yes & $62.45 \pm 5.25$ & -3.460 \\
\hline Attitudes Scale & No & $64.78 \pm 4.08$ & .001 \\
\hline \multicolumn{4}{|c|}{$\begin{array}{c}\text { Making milk donations to the breast } \\
\text { milk bank }\end{array}$} \\
\hline \multirow[t]{2}{*}{ Thoughts } & I would donate & $29.71 \pm 2.13$ & -1.122 \\
\hline & I would not donate & $30.05 \pm 1.87$ & .264 \\
\hline \multirow[t]{2}{*}{ Behaviors } & I would donate & $18.71 \pm 2.71$ & -1.585 \\
\hline & I would not donate & $19.50 \pm 2.82$ & .066 \\
\hline \multirow[t]{2}{*}{ Emotions } & I would donate & $14.65 \pm 1.70$ & -1.475 \\
\hline & I would not donate & $15.00 \pm 1.26$ & .142 \\
\hline Total score for the Religious & Yes & $63.07 \pm 5.05$ & -2.011 \\
\hline Attitudes Scale & No & $64.55 \pm 4.32$ & .046 \\
\hline \multicolumn{4}{|c|}{ Giving breast milk to others' babies } \\
\hline \multirow[t]{2}{*}{ Thoughts } & Yes & $30.10 \pm 1.79$ & -1.585 \\
\hline & No & $29.81 \pm 2.07$ & .066 \\
\hline \multirow[t]{2}{*}{ Behaviors } & Yes & $21.10 \pm 2.72$ & -2.540 \\
\hline & No & $18.85 \pm 2.73$ & .029 \\
\hline \multirow[t]{2}{*}{ Emotions } & Yes & $15.00 \pm 1.24$ & .614 \\
\hline & No & $14.75 \pm 1.60$ & .552 \\
\hline Total score for the Religious & Yes & $66.20 \pm 2.93$ & 2.180 \\
\hline Attitudes Scale & No & $63.41 \pm 4.91$ & .016 \\
\hline
\end{tabular}

It was determined that $95 \%$ of the parents $(\mathrm{n}=190)$ did not want to give their breast milk to others' children and that behavior subscale scores and total scale score of the mothers who did not want to give their milk to others' babies were statistically significantly higher $(\mathrm{p}<0.05)$ (Table 2).

It was determined that there was no statistically significant difference between the RAS scores of mothers in terms of their education level, employment status, family type, age, occupation, number of pregnancies, planned pregnancy, number of children, and number of pregnancies ( $p>0,05)$.

According to the standardized regression coefficient $(\beta)$, the order of the importance of the predictive variables on the religious orientation is as follows: mother's education; donating breast milk; hearing about HMB; family structure; mother's employment status; obtaining breast milk from the bank when needed; accepting milk from another mother; age; the rank of the pregnancy; milk donation to the HMB; and planned pregnancy (Table 3). When the test results were examined (In multiple regression analysis), it was found that the only variable that was a significant predictor on the religious attitude was "obtaining milk from the bank when needed". 
Table 3. Factors related to religious attitudes (N:200)

\begin{tabular}{|c|c|c|c|c|c|c|c|}
\hline Variables & $B$ & $\begin{array}{l}\text { Standard } \\
\text { Deviation }\end{array}$ & $\begin{array}{r}\text { Beta } \\
\left(R^{2)}\right.\end{array}$ & $t$ & $p$ & $r$ & $\begin{array}{c}\text { Partial } \\
r\end{array}$ \\
\hline Constant & 6.026 & 5.786 & - & 11.41 & 0.000 & - & - \\
\hline Age range & 0.069 & 0.075 & 0.86 & 0.927 & 0.35 & 0.582 & 1.719 \\
\hline $\begin{array}{l}\text { Employment of the } \\
\text { mother }\end{array}$ & -0.024 & 0.344 & -0.006 & -0.70 & 0.94 & 0.626 & 1.594 \\
\hline Education status & -0.466 & 0.338 & -0.118 & -1.376 & 0.170 & 0.660 & 1.50 \\
\hline Family type & -0.143 & 0.743 & -0.015 & -0.192 & 0.848 & 0.342 & 1.18 \\
\hline $\begin{array}{l}\text { Number of } \\
\text { pregnancies }\end{array}$ & 0.112 & 0.452 & -0.034 & -0.247 & 0.805 & 0.258 & 3.98 \\
\hline Rank of the child & 0.177 & 0.528 & 0.046 & 0.334 & 0.738 & 0.253 & 3.94 \\
\hline Planned pregnancy & 0.236 & 0.981 & 0.018 & 0.238 & 0.812 & 0.874 & 1.14 \\
\hline $\begin{array}{l}\text { Receiving husband } \\
\text { support during } \\
\text { pregnancy }\end{array}$ & -1.254 & 1.004 & -0.092 & -1.248 & 0.213 & 0.892 & 1.12 \\
\hline $\begin{array}{c}\text { Donating milk to } \\
\text { others' babies }\end{array}$ & -2.187 & 1.622 & -0.098 & -1.348 & 0.719 & 0.918 & 1.08 \\
\hline $\begin{array}{l}\text { Accepting milk from } \\
\text { others }\end{array}$ & 0.810 & 1.869 & 0.033 & 0.433 & 0.665 & 0.855 & 1.16 \\
\hline $\begin{array}{l}\text { Hearing about milk } \\
\text { banking }\end{array}$ & -0.716 & 0.797 & 0.070 & -0.898 & 0.370 & 0.811 & 1.23 \\
\hline $\begin{array}{l}\text { Approving a milk bank } \\
\text { in our country }\end{array}$ & -1.047 & 1.093 & -0.096 & -0.958 & 0.339 & 0.487 & 2.05 \\
\hline $\begin{array}{l}\text { Making milk donations } \\
\text { to a breast milk bank }\end{array}$ & 0.295 & 1.073 & 0.28 & 0.275 & 0.783 & 0.458 & 2.18 \\
\hline
\end{tabular}

\section{Discussion}

$\% 4$ of the mothers participating in this study stated that their infant had a wet-nurse. Despite the lack of data on how often wet-nursing is resorted to in our country, it was observed that wet-nursing was a still continuing traditional practice in our country. It was determined according to the reports of mothers (10.9\%) in Ekşioğlu et al. [14]; 8.7 \% in Ergin et al. [15]; and $14.7 \%$ in Can et al. [16] that at least one of the children in the family had a wet-nurse. When compared to these rates, it was observed that our rates were lower. This difference might have stemmed from the fact that the studies were carried out in different cities and sample groups.

$5 \%$ of the mothers in our study group had done wet-nursing before. Similarly, the rate of mothers doing wet-nursing was determined to be $17 \%$ in Can et al. [16], 12.5\% in Ergin et al. [15] and 8.2\% in Ekşioğlu et al. [14].

It was determined that HMB was known in some previous studies (90.6-41.6\% of the mothers) [14,15,17]. It was observed in our study group that more mothers $(95 \%)$ had heard of HMB compared to the results of this investigators. The increase in the proportion of mothers who were aware of HMB can be explained by the increase in the sensitivity, interest and scientific studies related to the topic.

While $73 \%$ of the mothers in our study group wanted a HMB in our country, it was determined that only $32 \%$ of the mothers were willing to donate breast milk to the bank and that $47.4 \%$ would not get milk from the bank when they could not give milk to their babies. Similarly, Karadag et al. [18] found that $42.4 \%$ of the mothers in their study did not want to get milk from the HMB. Even if the mothers found the opening of HMB favorable, it is thought that about half of them had concerns about using the bank for their own baby.

Similar to the mother in other studies, the mothers in our study group did not want to get milk donations because they wanted to know the donor well, they did not approve a milk kinship, the milk might transfer diseases, and they were jealous of the donor mother $[14,15,17]$. Approximately half of the mothers $(47.4 \%)$ stated that they would not give the breast milk of any mother to their babies without necessarily knowing the identity. This result shows that mothers prefer donor human milk when they know the family.

It was determined that the mothers with high religious orientation did not want to accept milk from the bank and neither did they want to make milk donations $(\mathrm{p}<0.05)$ (Table 2). In countries where the majority of the population is Muslim, attitudes 
towards HMB is different from those of European region. The most important reason for opposing HMB in Muslim countries is that marriage between people having a milk kinship is not considered appropriate due to the religious reasons.

Children who are breastfed by a donor mother are siblings with the children of the donor mother and cannot get married. However, some contemporary Islamic law scientists claim that milk banks can be established if a solution to this problem can be found. In our country, the Presidency of Religious Affairs states that human milk banks can be founded in the country provided that necessary measures are taken. However, there are no HMB in Turkey as legal arrangements haven't been made yet [10].

It was observed that the most important reason why mothers were unwilling to make milk donations to others' babies was "milk kinship". Although the mothers with babies in NICU found breast milk beneficial for the health and development of their babies and they said they would accept breast milk from others, the results of the study indicated that mothers were hesitant and that they rejected it due to religious and disease transmission reasons.

Majority of the mothers are confronted with the dilemma of "milk kinship" and the "need of their babies"[10,11]. Despite all these teachings, it was observed that majority of the mothers (95\%) did not want to donate their breast milk to others' babies, however, that religious orientation level of the mothers who wanted to donate milk was high ( $<<0.05)($ Table 2).

While this suggests that mothers' concerns and their religious orientations were influential on their milk donations, the issue still needs to be investigated on different groups.

In multiple regression analysis, "obtaining milk from the bank when necessary" was found to be an important predictor on religious orientation. Donor milk can be provided by removing the obstacles preventing breastfeeding, introducing donor and recipient mothers, giving the donated milk to a single child without mixing it with other donations, supplying the sides with donor and recipient information, establishing HMB on voluntary base, and informing the public.

\section{Conclusion}

According to the findings of the study, it was determined that the religious attitudes influenced mothers' attitudes towards HMB. It is important that healthcare workers, especially midwives, nurses, gynecologists, and pediatricians should provide information to donors and potential recipients. Involving HMB and donation issues in education should raise awareness of mothers.

\section{Acknowledgements}

The authors gratefully acknowledge all mothers for their collaboration. This research was not supported by any institution.

\section{Conflict of Interest}

The authors declare no conflict of interest.

\section{References}

[1] Bharadva K., Satish T., Mishra S., Mukhopadhyay K., Yadav B., Agarwal R.K, et al. Human Milk Banking Guidelines. Indian Pediatrics, 51(15):469-74, 2014.

[2] Arslanoglu S, Corpeleijn W, Moro G, Braegger C, Campoy C, Colomb V, et al. Donor human milk for preterm infants: current evidence and research directions. ESPGHAN Commentary. J Pediatr Gastroenterol Nutr, 57(4):535-42, 2013.

[3] Arslanoglu S, Moro GE, Bell ù R, Turoli D, De Nisi G, Tonetto P, et al. Presence of human milk bank is associated with elevated rate of exclusive breastfeeding in VLBW infants. J Perinat Med, 41(2):129-31, 2013.

[4] Boyd CA, Quigley MA, \& Brocklehurst P. Arch Dis Child Fetal Neonatal Ed, 92(3),F169-75. 2007.

[5] Goldenberg RL, Culhane JF, Iams JD, \&Romero R. Epidemiology and causes of preterm birth. Lancet, 371,75- 84, 2008.

[6] American Academy of Pediatrics (AAP). Policystatement Breastfeeding and the Use of Human Milk Section on breastfeeding. Pediatrics, 129, e827-41, 2012. 
[7] Azema E, \& Callahan S. Breast milk donors in France: a portrait of thetypical donor and the utility of milk banking in the French breastfeeding context. J Hum Lact, 19,199-202, 2003.

[8] Kim JH, \& Unger S. Canadian Paediatric Society, Nutrition and Gastroenterology Committee. Human milk banking. Paediatr Child Health, 15(9),595-98, 2010.

[9] Torres MIU, López CM, Román V, Díaz CA, Cruz-Rojo J, Cooke E.F., et al. Does opening a milk bank in a neonatal unit change infant feeding practices? A before and after study. International Breastfeeding Journal, 5:4, 2010.

[10] Pekdemir Ş..Human milk banks in Islamic law. JASSS, 40:537-54, 2015.

[11] AL-Naqeeb NA, Azab A, Eliwa MS, \& Mohammed BY. The Introduction of Breast Milk Donation in a Muslim Country. Journal of Human Lactation, 16(4),346-50, 2000.

[12] Forster DA McLachlan HL. Women's views and experiences of breast feeding: positive, negative or just good for the baby? Midwifery, 26(1), 116-25, 2010.

[13] Onay A. Dini Yönelim Ölçeği: Ölçek geliştirmede yöntem, teorik altyapı, geçerlilik ve güvenilirlik (Religious orientation scale- Scale working method: Theoretical background,validity and reliability), İslamiyat Dergisi, 5(4),181-192, 2002.

[14] Ekşioğlu A, Yeşil Y, \& Turfan EÇ. Mothers' views about milk banking: The case of İzmir City. Turkish Archives of Pediatrics, 50,83-89, 2015.

[15] Ergin A, \& Uzun SU. Turkish Women's Knowledge, Attitudes, and Behaviors on Wet-Nursing, Milk Sharing and Human Milk Banking. Matern Child Health J, 22(4),454-60, 2018.

[16] Can HO, Yesil Y, Eksioglu A, \& Turfan EC. Women's views on wet nursing and milk siblinghood: an example from Turkey. Breastfeed Med, 9(10), 559-60, 2014.

[17] Gürol A, Özkan A, \& Çelebioğlu A. Turkish Women's knowledge and views regarding breast milk banking. Collegian, 21(3), 239-44, 2014.

[18] Karadag A, Ozdemir R, Ak M, Ozer A, Dogan DG, \& Elkiran E. Human milk banking and milk kinship: Perspectives of mothers in a Muslim country Journal of Tropical Pediatrics, 61,188-96, 2015. 